\title{
Individual Variation in Semen Characteristics of Murrah Buffalo Bulls
}

\author{
Nurul Isnaini, Tri Harsi, Sandy Eka Kurnianto
}

\begin{abstract}
This study evaluated the variation in semen characteristics between two individual Murrah buffalo bulls. Two hundred and ninety semen samples were involved in this study. The results showed that most of the semen had a milky white color with moderate consistency. The Bull B1 tended to have higher proportion of creamy color and moderate consistency than the Bull B2. The ejaculatory volume is varied $(P<0.01)$ between Bull B1 and Bull B2. However, semen pH and sperm concentration of Bull $B 1$ and $B 2$ were equal $(P>0.05)$. The individual bull had a highly significant effect $(P<0.01)$ on sperm motility of fresh semen. The individual variation $(P<0.05)$ also found on sperm motility of before freezing. Whereas, sperm motility of post-thawing semen and recovery rate value were not significantly influenced (P>0.05). Moreover, it was found that the frozen semen production differed $(P<0.01)$ between two individual bulls, with bull B1 had higher production than the bull B2. This study clearly demonstrates that the frozen semen production of Murrah buffalo is highly dependent on the individual bull. However, the variation in frozen semen production between two bulls studied here is still qualified to be used for artificial insemination.
\end{abstract}

Keywords: genetic potential, individual variation, Murrah buffalo, reproductive performance, semen quality.

\section{INTRODUCTION}

B uffalo is a meat- and milk-producing livestock that can be used to fulfill food demand for the society. Buffalo has the advantage in digesting feed with high fiber content such as rice straw. However, the ability of buffalo to convert excess energy to fat is very limited so that the body weight gain of buffalo is relatively low. One type of buffalo in Indonesia is Murrah buffalo, which is native to India and Egypt. Gerli et al. [1] stated that the population Murrah buffalo is relatively low because of only about $5 \%$ of the total buffalo population in Indonesia. This type of buffalo mostly reared in the North Sumatera area.

To increase the population of Murrah buffalo, it is necessary to have a superior bull who has merit genetic potential, both in terms of growth traits and semen production so that it can facilitate the implementation of

Revised Manuscript Received on January 5, 2020.

* Correspondence Author

Nurul Isnaini*, Department of Animal Production, Faculty of Animal Science, University of Brawijaya, Malang 65145, Indonesia. Email: nurulisna@ub.ac.id

Tri Harsi, Lembang Artificial Insemination Center, Bandung 40391, Indonesia. Email: tri.harsi@pertanian.go.id

Sandy Eka Kurnianto, Department of Animal Production, Faculty of Animal Science, University of Brawijaya, Malang 65145, Indonesia. Email: cyborgsandy@gmail.com artificial insemination programs. Artificial insemination is a reproductive biotechnology using semen from the selected bull. This technology aims to obtain superior offspring, improve economic efficiency, avoid inbreeding, and avoid disease transmission [2,3]. The success of implementing artificial insemination largely depends on the semen quality [4]. Fresh semen has a relatively short life span so that it needs to be cryopreserved to increase the durability. However, the cryopreservation process can reduce the quality of spermatozoa due to the extreme temperatures during freezing [5].

The development of artificial insemination is now widely spread throughout Indonesia. This is because the farmer has realized the benefits of artificial insemination to increase livestock productivity. The crucial role of artificial insemination made almost every province in Indonesia, through the Agency of Livestock and Animal Health, establish an Artificial Insemination Center or Technical Implementation Unit of Artificial Insemination. The Artificial Insemination Center has an important role in producing semen with superior quality, starting from the process of fresh semen collection, fresh semen quality evaluation, until the frozen semen production process, in which all of these activities will affect the success of artificial insemination. Artificial Insemination Center also has an important role in the selection and rearing of livestock so that they could produce semen optimally. In selecting superior bulls, several factors need to be considered. Semen quality of bull can be influenced by several factors, including genetic traits, bull age, season, ejaculation frequency, and feed $[6,7,8]$. The purpose of this study was to evaluate the individual variation in semen characteristics of Murrah buffalo bulls in Lembang Artificial Insemination Center.

\section{MATERIALS AND METHODS}

A total of 2 Murrah buffalo bulls were involved in this study. Both of bull was at the same age of 5 years. The bulls were kept at Lembang Artificial Insemination Center, Bandung, Indonesia, under identical nutritional and management conditions.

A total of 290 ejaculates, 149 ejaculates of bull B1 and 141 ejaculates of bull B2, were involved in this study. Semen collection was carried out from January 2017 to August 2018. Soon after collection, semen was sent to the laboratory. The assessment of semen quality including semen color, consistency, volume, $\mathrm{pH}$, concentration, sperm motility at three different stages (fresh, before-freezing,

and

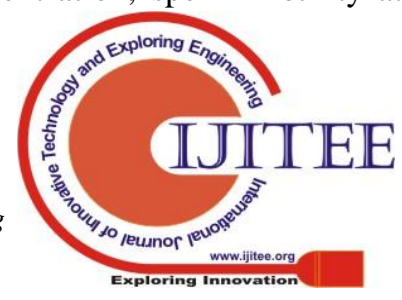


post-thawing), the recovery rate, and frozen semen production.

Data of semen color and consistency were analyzed descriptively. While other traits were compared using independent t-test (for normally distributed data) or Mann Whitney test (for not normally distributed data). Data were regarded as significant or highly significant differences when $\mathrm{P}<0.05$ or $\mathrm{P}<0.01$, respectively.

\section{RESULT AND DISCUSSION}

The physical appearance of semen ejaculated by different individual Murrah buffalo bulls studied here is presented in Table I. Most of the semen had a milky white color with moderate consistency. The Bull B1 tended to have preferable physical semen characteristics as indicated by a higher proportion of creamy color and moderate consistency than the Bull B2. In a study by Catunda et al. [9], it was showed that creamy semen had higher sperm concentration and mass motility. Kanchan and Matharoo [10] also observed that semen with creamy color had higher initial sperm motility than those with milky color.
The effect of the individual bull on semen quality of Murrah buffalo is shown in Table II. The results showed that the ejaculatory volume is varied $(\mathrm{P}<0.01)$ between Bull B1 and Bull B2 (Table II). However, bull B1 and B2 had equal $(\mathrm{P}>0.05)$ semen $\mathrm{pH}$ and sperm concentration. On the other hand, sperm motility of fresh semen $(\mathrm{P}<0.01)$ and before freezing semen $(\mathrm{P}<0.05)$ were differed between bull $\mathrm{B} 1$ and B2. However, sperm motility of post-thawing semen and recovery rate value were not significantly influenced $(\mathrm{P}>0.05)$. Moreover, it was found that the frozen semen production was differed $(\mathrm{P}<0.01)$ between two individual bulls.

Table I. Effect of the individual bull on the physical appearance of Murrah buffalo's semen

\begin{tabular}{|c|c|c|}
\hline Traits & Bull B1 & Bull B2 \\
\hline Semen color (\%) & & \\
\hline Creamy & 44.30 & 39.01 \\
\hline Milky white & 55.70 & 59.57 \\
\hline Abnormal & 0.00 & 1.42 \\
\hline Semen consistency (\%) & & \\
\hline Watery & 29.53 & 37.59 \\
\hline Moderate & 70.47 & 62.41 \\
\hline Dense & 0.00 & 0.00 \\
\hline
\end{tabular}

Table II. Effect of the individual bull on semen quality of Murrah buffalo

\begin{tabular}{|l|c|c|c|}
\hline Traits & Bull B1 & Bull B2 & Significance \\
\hline Ejaculatory volume (ml) & $4.25 \pm 1.40$ & $3.55 \pm 1.34$ & $* *$ \\
\hline Semen pH & $6.72 \pm 0.16$ & $6.70 \pm 0.18$ & NS \\
\hline Sperm concentration (million) & $1,143.34 \pm 262.93$ & $1,113.01 \pm 342.92$ & NS \\
\hline Sperm motility & & & \\
\hline Fresh semen (\%) & $68.62 \pm 7.95$ & $64.08 \pm 13.38$ & $* *$ \\
\hline Before freezing (\%) & $60.32 \pm 9.35$ & $53.97 \pm 19.40$ & $*$ \\
\hline Post-thawing (\%) & $40.56 \pm 1.70$ & $40.78 \pm 1.97$ & NS \\
\hline Recovery rate (\%) & $57.62 \pm 2.53$ & $57.65 \pm 3.23$ & NS \\
\hline Frozen semen production (straw) & $179.71 \pm 60.51$ & $146.66 \pm 59.08$ & $* *$ \\
\hline
\end{tabular}

Data are shown as mean \pm standard deviation

NS: Not significantly different $(\mathrm{P}>0.05), *$ : Significantly different $(\mathrm{P}<0.05), * *$ : Highly significant different $(\mathrm{P}<0.01)$.

In line with this finding, Andrabi [11] also noticed that the semen quality in buffalo was influenced by the individual bull. The existence of different semen production probably due to the variation in genetic potential between individual bulls. Previously, it was also observed that the semen quality was highly dependent by individual male sire in other livestock such as horse [12], cattle [6], and goat [9].

In this current finding, it should be emphasized that the semen quality parameters of bull B1 and B2 were still in the standard range. As previously reported by Andrabi [11], semen volume and sperm concentration of Murrah buffalo bulls were ranged from 2.0 to $8.0 \mathrm{ml}$ and 320 million to 5.9 billion, respectively. Mahmoud et al. [13] observed that sperm concentration of buffalo bull was ranged from 1.02 to $1.17 \mathrm{billion} / \mathrm{ml}$, while their sperm motility was ranged from 65.00 to $68.30 \%$ (fresh semen) and from 39.33 to $45.87 \%$ (post-thawing semen). For that reason, the variation of frozen semen production between two bulls could not inhibit the use of both bulls for artificial insemination. Additionally, both of Bull B1 and B2 had a similar result on post-thawing sperm motility, which was previously categorized as the best single predictor for field fertility of buffalo $[14,15]$.
Moreover, the sperm motility in post-thawing semen sample of buffalo bull obtained in this study may result in similar field fertility, as noted by Mahmoud et al. [13] that buffalo bull's semen with post-thawing sperm motility between 39.33 and $43.84 \%$ had a similar result on pregnancy rate. For those reasons, both of Bull B1 and B2 have the potency to be used as male sire for artificial insemination.

\section{CONCLUSION}

The conclusion of this study is that the frozen semen production of Murrah buffalo is highly dependent on the individual animal. However, frozen semen production of two bulls studied here is still qualified to be used in artificial insemination program.

\section{ACKNOWLEDGMENT}

The authors gratefully acknowledge facility support from Lembang Artificial Insemination Center.

\section{REFERENCES}

1. H. Gerli and A. H. Daulay, "Characteristics of body size of the 
Murrah bufallo and swamp buffalo in BPTU Siborongborong," Jurnal Peternakan Integratif, vol. 1, Dec. 2013, pp. 276-287. (in Indonesian)

2. M. G. Diskin, "Semen handling, time of insemination and insemination technique in cattle," Animal, vol. 12, Jun. 2018, pp. s75-s84.

3. A. Mohammed, "Artificial insemination and its economical significancy in dairy cattle,” Int. J. Res. Stud. Microbiol. Biotechnol., vol. 4, 2018, pp. $30-43$.

4. S. K. Rabidas, A. K. Talukder, M. Alam, G. Shahi, and F. Y. Bari, "Relationship between semen quality parameters and field fertility of bulls," J. Anim. Reprod. Biotechnol., vol. 27, Mar. 2012, pp. 21-28.

5. S. Ahmed, M. I. U. R. Khan, M. Ahmad, and S. Iqbal, "Effect of age on lipid peroxidation of fresh and frozen-thawed semen of Nili-Ravi buffalo bulls," Ital. J. Anim. Sci., vol. 17, Jul. 2018, pp. 730-735.

6. M. Bhakat, T. K. Mohanty, V. S. Raina, A. K. Gupta, H. M. Khan, R. K. Mahapatra, and M. Sarkar, "Effect of age and season on semen quality parameters in Sahiwal bulls," Trop. Anim. Health Prod., vol. 43, Aug. 2011, pp. 1161-1168.

7. A. K. Singh, S. K. Rajak, P. Kumar, S. Kerketta, and R. K. Yogi, "Nutrition and bull fertility: A review," J. Entomol. Zool. Stud., vol. 6, Nov. 2018, pp. 635-643.

8. N. Isnaini, S. Wahjuningsih, A. Ma'ruf, and D. A. Witayanto, "Effects of age and breed on semen quality of beef bull sires in an Indonesian artificial insemination center," Livest. Res. Rural Dev., 31, May 2019, p. 78.

9. A. G. V. Catunda, G. V. Aguiar, I. C. S. Lima, J. F. Pereira, R. S. S Pitombeira, I. R. A. Andrade, G. A. Martins, C. E. A. Souza, J. F. Nunes, A. A. N. Moura, and A. C. N. Campos, "Characterization of ejaculates from crossbreed male goats raised in tropical environment," Rev. Port. Ciênc. Vet., vol. 106, Jan. 2011, pp. 59-67.

10. Kanchan and J. S. Matharoo, "Effect of semen colour on seminal characteristics in cattle bulls," Indian J Anim. Res., vol. 49, Feb. 2015, pp. 146-147.

11. S. M. H. Andrabi, "Applied andrology in water buffalo," In Animal Andrology: Theories and Applications, P. J. Chenoweth and S. Lorton, Eds. Oxfordshire: CABI, 2014, pp. 380-403.

12. F. Janett, R. Thun, S. Bettschen, D. Burger, and M. Hassig, "Seasonal changes of semen quality and freezability in Franches-Montagnes stallions," Anim. Reprod. Sci., vol. 77, Jul. 2003, pp. 213-221.

13. K. Mahmoud, A. A. E. El-Sokary, M. E. A. Abou El-Roos, A. D. Abdel Ghaffar, and M. Nawito, "Sperm characteristics in cryopreserved buffalo bull semen and field fertility," Iran. J. Appl. Anim. Sci., vol. 3, Dec. 2013, pp. 777-783.

14. H. Ahmed, S. M. H. Andrabi, and S. Jahan, "Semen quality parameters as fertility predictors of water buffalo bull spermatozoa during low-breeding season," Theriogenology, vol. 86, Oct. 2016, pp. 1516-1522.

15. H. Ahmed, S. M. H. Andrabi, M. Anwar, and S. Jahan, "Use of post-thaw semen quality parameters to predict fertility of water buffalo (Bubalus bubalis) bull during peak breeding season," Andrologia, vol. 49, May 2017, e12639.

\section{AUTHORS PROFILE}

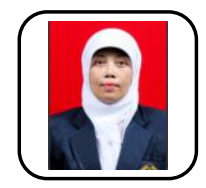

Nurul Isnaini, is a lecturer in Department of Animal Production, Faculty of Animal Science, University of Brawijaya, Indonesia. She has received a doctoral degree in Animal Science from University of Brawijaya. She has published 13 research papers in international reputable journal. Her research interest in animal reproduction.

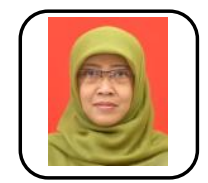

Tri Harsi, is head of Lembang Artificial Inseminaton Center, Indonesia. She has received a master degree from Faculty of Animal Science, Jenderal Soedirman University.

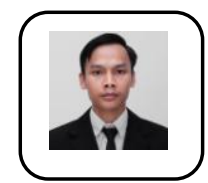

Sandy Eka Kurnianto, is a student in Bachelor Degree of Animal Science, Faculty of Animal Science, University of Brawijaya, Indonesia. 